\title{
Vacuum-Assisted Closure Therapy for the Treatment of Poststernotomy Wound Dehiscence in Neonates and Infants
}

\author{
Federico Lo Torto ${ }^{1}$ Gianmarco Turriziani ${ }^{1}$ Fabio Miraldi ${ }^{1}$ Bruno Carlesimo ${ }^{2}$ Diego Ribuffo ${ }^{1}$
}

1 Umberto I Policlinico di Roma, Roma, Italy

2 Università degli Studi di Roma La Sapienza Facoltà di Medicina e

Address for correspondence Gianmarco Turriziani, Università degli Odontoiatria, Roma, Lazio, Italy Studi di Roma La Sapienza Facoltà di Medicina e Odontoiatria, Roma, Lazio, Italy (e-mail: gianmarco.turriziani@gmail.com).

Thorac Cardiovasc Surg

ERRATUM
It has been brought to the Publisher's attention that the first author's family name was not tagged correctly in the above-mentioned article, published on eFirst on April 19, 2019. DOI of the original article is DOI: $10.1055 / \mathrm{s}-0039-1685543$. The name should be listed with "Federico" as first name and "Lo Torto" as family name. (c) Georg Thieme Verlag KG

Stuttgart · New York
DOI https://doi.org/ 10.1055/s-0039-1688958. ISSN $0171-6425$. 